Jurnal Inkofar * Volume 1 No. 2 Desember 2020 * ISSN: 2615-3645 (Print) / 2581-2920 (Online)

Tersedia secara online di: http://www.politeknikmeta.ac.id/meta/ojs/

\title{
PERBAIKAN DESAIN FRAME PICK UP RIGHT UNTUK MEREDUKSI CACAT PADA PROSES INJECTION MOLDING
}

\author{
Agus Widodo \\ Program Studi Teknik Mesin, Institut Sains Dan Teknologi Nasional Jakarta \\ widodoagus586@gmail.com
}

\begin{abstract}
This study discusses the failure of injection molding products in the form of defects that occur in frame pick up right products. The purpose of this study is intended to reduce the defect. The use of polypropylene plastic materials is growing, demanding efforts to reduce time and production costs caused by product defects. In the product of injection molding products often occur product defects, such as cracks, shrinkage in certain parts, imperfect shapes, dissolution of plastic material, dimensions of the product beyond the specified tolerance and so forth. The problem that often arises in the injection molding process is the influence of injection temperature and pressure. When production, the trial process is needed repeatedly to get the perfect setting for an injection molding product. Based on visual data and supporting data in the field, some of the main causes of this defect, may be caused by material incompatibility \& mold design. The industry is now undeniable that most still use the old patterns in making molds and their production processes. Still relying on the skills and knowledge of mold engineers and injection engineers in handling a problem in its production. With the simulation of the mold flow in mold making really helps the industry in the work of molds and accelerates the production process of a product.
\end{abstract}

Keywords : frame pick up right, polypropylene, defect, injection molding, mold flow

\begin{abstract}
ABSTRAK
Penelitian ini membahas kegagalan produk injection molding berupa cacat yang terjadi pada produk frame pick up right. Tujuan penelitian ini dimaksudkan untuk mereduksi dari cacat tersebut. Penggunaan material plastik polypropylene yang semakin berkembang, menuntut usaha untuk mengurangi waktu dan biaya produksi yang diakibatkan oleh cacat produk. Pada produk hasil injection molding sering terjadi cacat produk, seperti keretakan, penyusutan pada bagian-bagian tertentu, bentuk tidak sempurna, peluberan material plastik, dimensi produk diluar dari toleransi yang ditentukan dan lain sebagainya. Permasalahan yang sering timbul pada proses injection molding adalah pengaruh temperatur dan tekanan injeksi. Saat produksi dibutuhkan proses trial yang berulang- ulang hingga mendapatkan pengaturan yang sempurna untuk suatu produk injection molding. Berdasarkan data visual dan data pendukung di lapangan, beberapa penyebab utama adanya cacat ini, kemungkinan disebabkan oleh ketidak cocokan material \& desain mold. Industri saat ini tidak dipungkiri sebagian besar masih memakai pola lama dalam membuat mold dan proses produksinya . Masih mengandalkan ketrampilan dan pengetahuan mold engineer daninjection engineer dalam menangani sebuah masalah dalam produksinya. Dengan adanya simulasi mold flow dalam pembuatan mold sangat membantu industri dalam pengerjaan mold dan mempercepat proses produksi suatu produk .
\end{abstract}

Kata kunci : frame pick up right, polypropylene, cacat, injection molding, mold flow 


\section{PENDAHULUAN}

Pembuatan produk dengan material plastik menggunakan mesin injection molding saat ini erat hubungannya dengan perkembangan teknologi. Produk hasil injection molding sering terjadi cacat produk, seperti keretakan, penyusutan pada bagian-bagian tertentu, bentuk tidak sempurna, peluberan material plastik, dimensi produk diluar dari toleransi yang ditentukan dan lain sebagainya yang diakibatkan oleh beberapa faktor.

Penelitian mengenai minimalisasi cacat dengan pengaturan tekanan terhadap kualitas produk injection molding dengan menggunakan simulasi pernah dilakukan oleh Ratmono (2017). Dalam penelitiannya, Ratmono (2017) dimana proses untuk desain mold dan penentuan parameter injeksi masih belum dioptimalkan. Hal ini berakibat masih sering terjadi cacat produk plastik pada proses injeksi. Kualitas hasil injeksi tergantung pada pengalaman mold engineer dan injection engineer. Jika produk memiliki tingkat kerumitan yang tinggi, maka akan sangat sulit menghasilkan produk injeksi yang baik. Saat proses trial injeksi pada produk, masih ditemukan cacat produk berupa flash, shrinkage, dan warpage dsb. Kemungkinan solusi yang bisa diberikan adalah dalam hal optimasi pengaturan parameter injeksi.

Naik dkk, (2014) memberikan informasi mengenai cara meminimalkan cacat sink mark dengan proses injection molding menggunakan metode Taguchi. Pada penelitian ini menghasilkan variasi parameter yang paling berpengaruh terhadap sink mark seperti temperatur leleh, kecepatan injeksi, tekanan injeksi, waktu pendinginan untuk mengurangi terjadinya cacat sink mark. Penelitian yang hampir sama dilakukan oleh Kale dkk, (2013: 2) mengenai optimalisasi parameter proses dengan injection molding untuk meminimalkan shrinkage pada material high density polyethylene (HDPE) dengan hasil nilai shrinkage sebesar $0,515 \%$, dengan variasi parameter yang digunakan seperti temperatur leleh, tekanan injeksi, waktu pendinginan, dan tekanan pengepakan (pemampatan cairan plastik), yang berpengaruh untuk mengurangi terjadinya shrinkage. Dengan adanya simulasi ini diharapkan bisa mengurangi waktu yang biasa terjadi karena memakai desain konvensional Yang tidak boleh dilupakan adalah pentingnya desain ulang untuk mengatasi cacat yang terjadi pada produk . Dengan adanya simulasi mold flow dalam pembuatan mold sangat membantu industri dalam pengerjaan mold dan mempercepat proses produksi suatu produk.

\section{METODOLOGI PENELITIAN}

Pada penelitian Perbaikan Desain Frame Pick Up Right untuk Mereduksi Cacat Pada Proses Injection Molding di PT Sanwa Engineering ini diperlukan dukungan studi literatur yang berkaitan dengan analisis kerusakan dan pencegahannya khususnya yang berkaitan dengan cacat flash dan shrinkage produk frame pick up right. Pengumpulan data primer dan pendukung dengan cara melakukan survei untuk melakukan investigasi dan identifikasi masalah. Inspeksi lapangan atau observasi langsung yaitu pengambilan produk cacat flash dan shrinkage produk frame pick up right. Dengan memakai desain konvensional cukup banyak waktu yang terbuang karena banyaknya masalah yang muncul. Untuk itulah dengan adanya simulasi ini ini bisa membantu Industri dalam mendesain produk sehingga bisa lebih cepat dalam proses trial dan produksinya. 
Jurnal Inkofar * Volume 1 No. 2 Desember 2020 * ISSN: 2615-3645 (Print) / 2581-2920 (Online)

Tersedia secara online di: http://www.politeknikmeta.ac.id/meta/ojs/

\section{HASIL DAN PEMBAHASAN}

Tabel 4.1 Data Spesifikasi Produk

\begin{tabular}{|l|c|c|}
\hline Nama Produk & & Frame Pick Up Right \\
\hline Dimensi & $\mathrm{mm}$ & $98,4 \times 57,75 \times 20,11$ \\
\hline Massa & $\mathrm{g}$ & 13,820 \\
\hline Bahan Baku & & Polypropylene \\
\hline
\end{tabular}

Tabel 4.2 Karakteristik Polypropylene

\begin{tabular}{|l|l|l|}
\hline Berat Jenis & $\mathrm{gr} / \mathrm{cm}^{2}$ & $0,90-0,91$ \\
\hline Cylinder Temperature & ${ }_{C}$ C & $180-300$ \\
\hline Mold Temperature & ${ } C$ & $20-90$ \\
\hline Injection Pressure & $\mathrm{kg} / \mathrm{cm}^{2}$ & $600-1410$ \\
\hline
\end{tabular}

Parameter proses yang didapat dari perhitungan manual, data parameter PT. XYZ maupun hasil analisis molding window dari desain 1 dan desain 2 disimulasikan dengan Software Autodesk Simulation Moldflow Adviser 2013. Parameter proses pengujian desain 1 dan desain 2 disajikan dalam bentuk tabel, yang dapat dilihat pada tabel 4.6 dan tabel 4.7.

Manual : Parameter yang dihasilkan dari perhitungan manual

Advice : Parameter yang disarankan oleh Software Autodesk Simulation Moldflow 2013

Variasi : Parameter yang dipilih dengaan mengacu pada hasil simulasi yang dilakukan dengan parameter PS 12, manual, dan advice

Didapatkan fill time dan rasio shrinkage yang berbeda pada tiap pengujian, yang akan dibandingkan dan ditampilkan dalam bentuk grafik untuk mengetahui hasil simulasi dengan parameter terbaik . Dengan adanya simulasi ini terbukti mampu memperbaiki hasil trial produksi lebih cepat dibanding yang dulu.

1) Fill time

Hasil simulasi pada desain 1 dan desain 2, memiliki interval waktu yang cukup tinggi:

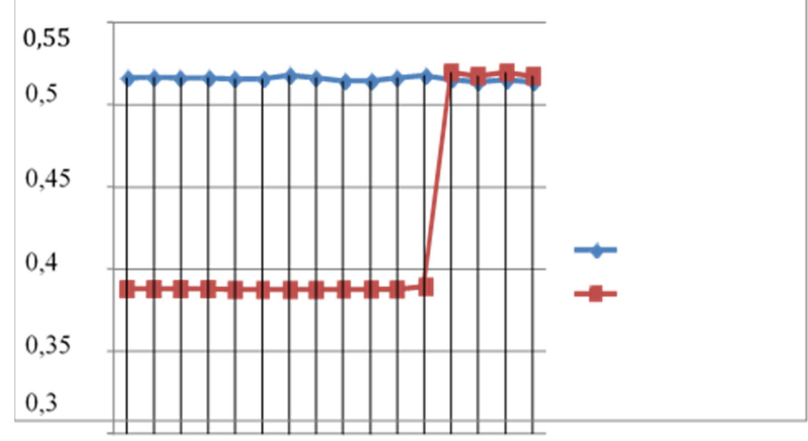

(C) 2020, Jurnal InkofarAll Rights Reserved 
Jurnal Inkofar * Volume 1 No. 2 Desember 2020 * ISSN: 2615-3645 (Print) / 2581-2920 (Online)

Tersedia secara online di: http://www.politeknikmeta.ac.id/meta/ojs/

2) Shrinkage Ratio

Hasil analisis shrink ratio pada desain 1 dan desain 2 ditampilkan dalam bentuk grafik pada gambar 4.7.

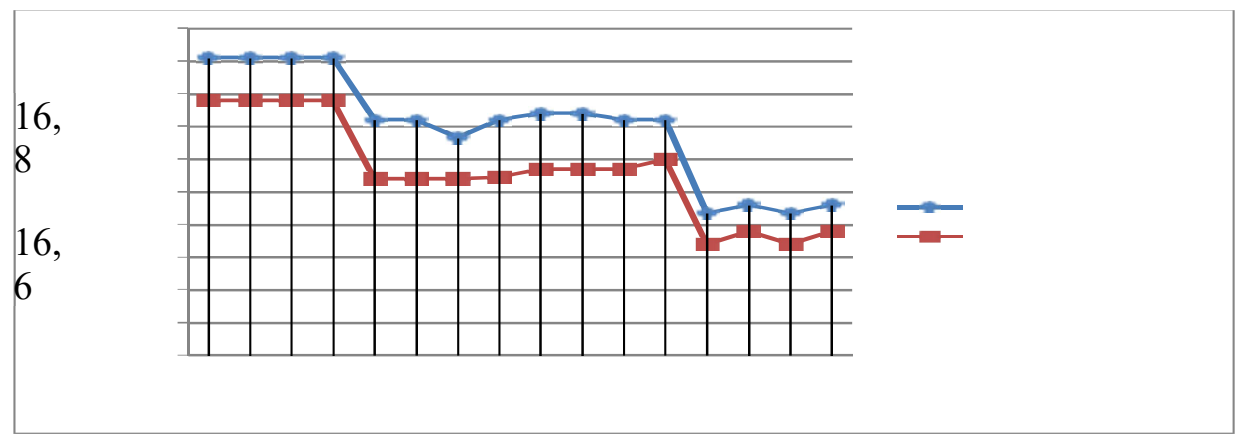

Gambar 4.9 Grafik Analisis Shrink ratio

Gambar 4.7 menunjukan bahwa desain 2 memiliki nilai shrink ratio lebih rendah daripada desain 1. Nilai shrink ratio terendah pada desain 1 memiliki nilai sebesar $15,87 \%$ pada pengujian 13 dan pengujian 15 dengan cylinder temperatur sebesar $230^{\circ} \mathrm{C}$, sedangkan nilai shrink ratio terendah pada desain 2 memiliki nilai sebesar $15,68 \%$ pada pengujian 13 dan pengujian 15 dengan cylinder temperatur sebesar $230^{\circ} \mathrm{C}$. Mengacu pada hal tersebut maka dapat disimpulkan bahwa cylinder temperatur berpengaruh terhadap cacat shrinkage yang dihasilkan pada produk. Cylinder temperatur yang tinggi akan menghasilkan rasio shrinkage yang besar, sebaliknya, cylinder temperatur yang rendah akan menghasilkan rasio shrinkage yang kecil.

\section{GAMBAR}

\subsection{Analisis Fill time}

Hasil simulasi filling time dengan menggunakan parameter data yang disajikan dalam tabel 4.6 dan tabel 4.7 menunjukan bahwa pada desain 1 waktu tercepat 0,5137 detik dengan cylinder temperatur sebesar $230^{\circ} \mathrm{C}$ dan injection pressure sebesar 69,14 Mpa.
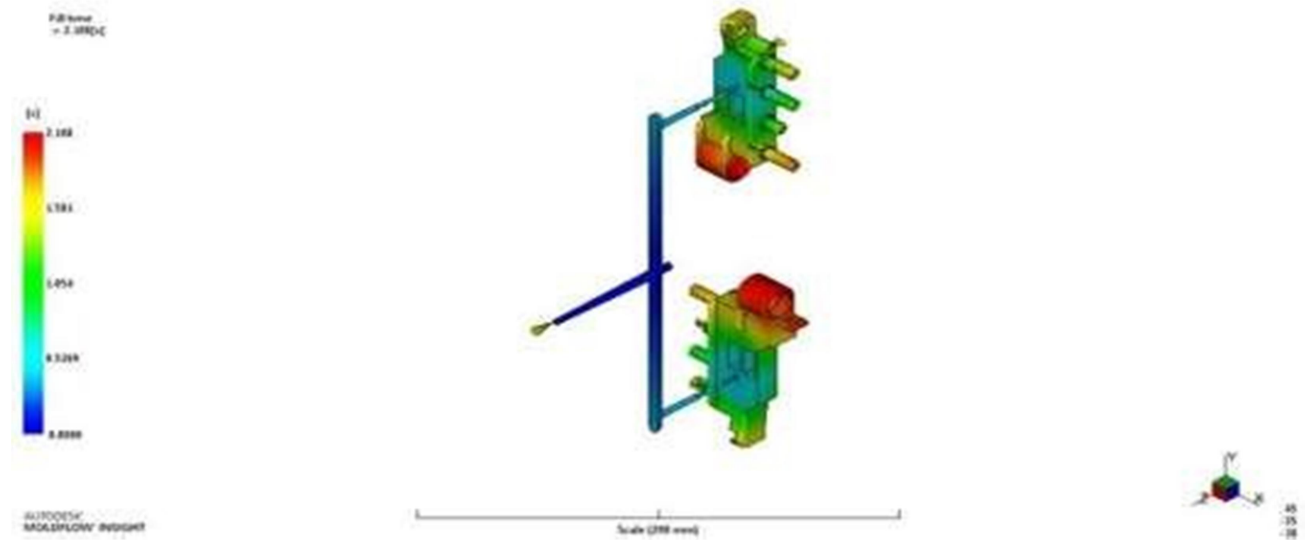

Dimana proses pengisian ke seluruh rongga mold terjadi secara bertahap yang ditunjukan dengan perbedaan warna. Distribusi material plastik leleh terjadi secara merata disetiap sisi, hal ini ditunjukan dengan tidak adanya indikasi overpacking dari hasil simulasi. Pada hasil 
pengujian desain 2 menunjukan waktu tercepat proses pengisian rongga cavity 0,3873 detik pada parameter cylinder temperatur sebesar $240^{\circ} \mathrm{C}$.

\subsection{Analisa Shrinkage}

Dari tabel 4.6 dan tabel 4.7 menunjukkan bahwa injection pressure tidak berpengaruh terhadap rasio shrinkage. Hal ini dibuktikan dengan nilai rasio shringkage yang tidak memiliki selisih yang jauh seperti pada rasio shrinkage pada tabel 1 dengan variasi injection pressure sebesar 60 Mpa, 69,14 Mpa, 98,56 Mpa, dan $128 \mathrm{Mpa}$ dengan cylinder temperatur sebesar $250^{\circ} \mathrm{C}$, yang menghasilkan rasio shrinkage yang seragam yaitu $16,56 \%$ juga terjadi pada hasil simulasi desain 2 dengan variasi injection pressure sebesar $60 \mathrm{Mpa}$, 69 Mpa, 98,56 Mpa dan $128 \mathrm{Mpa}$ dengan cylinder temperatur sebesar $250^{\circ}$. Hasil analisis pada produk frame pick up right menunjukan hasil dengan warna biru tua sebagai titik injeksi terbaik, warna kuning berpotensi shrinkage dan warna merah masih bermasalah. Maka pada desain titik injeksi berada pada area runner dari produk frame pick up right .
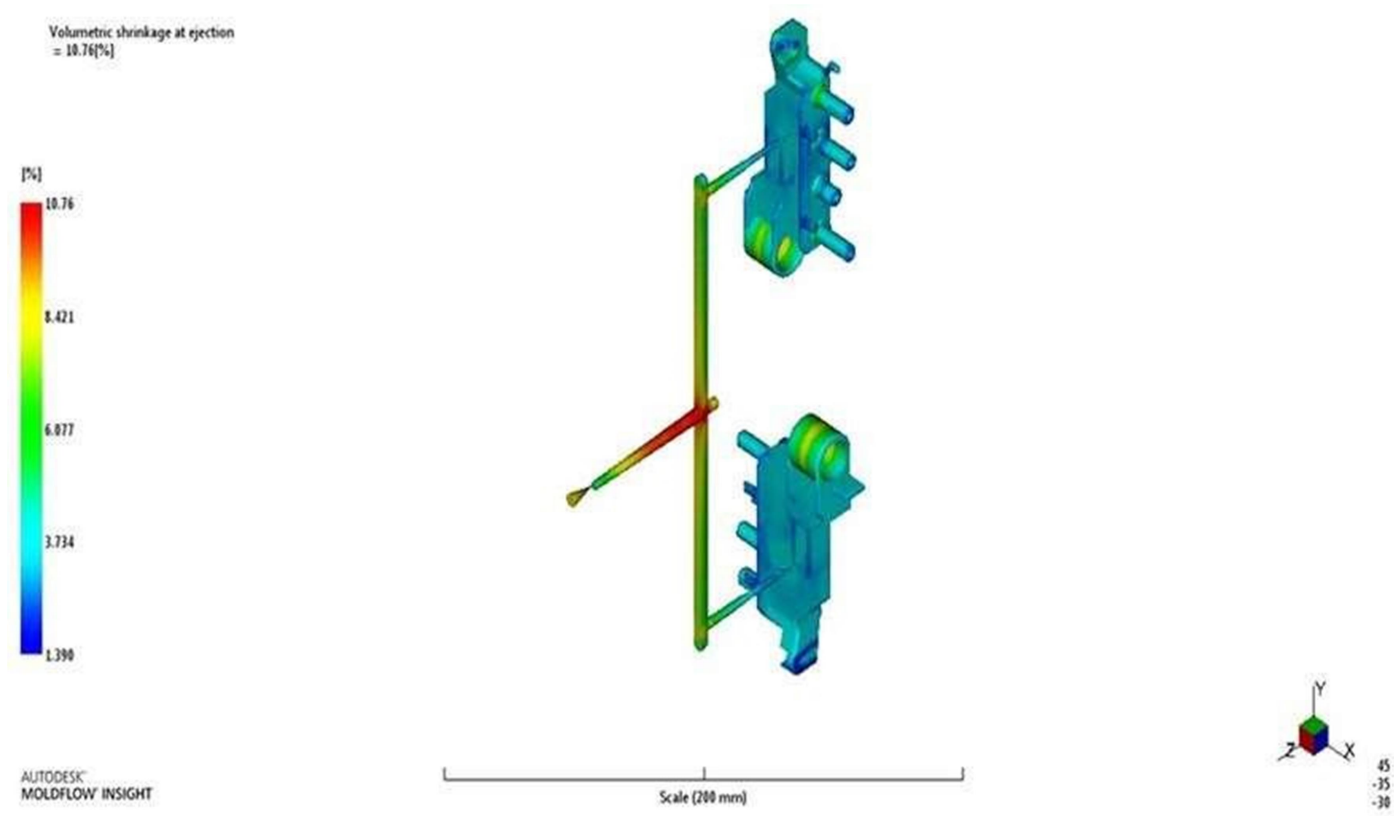

\section{KESIMPULAN DAN SARAN}

Dari hasil penelitian pemakaian simulasi dengan menggunakan software Autodesk Simulation Moldflow 2013, sewaktu proses produksi frame pick up right di injection molding didapatkan kesimpulan saran sebagai berikut:

a. Dengan software mold flow dapat mengoptimalkan ketebalan material pada produk agar pada waktu pengisian didapat hasil yang seragam, dapat mengoptimalkan waktu, dan mengurangi biaya produksi

b. Melalui penggunaan simulasi software mold flow dapat memprediksi cacat proses dan parameter injection mold seperti tekanan, temperatur .

c. Dalam mendesain cetakan produk plastik, sebaiknya dilakukan simulasi terlebih dahulu, dengan tujuan meminimalisir timbulnya cacat. Sehingga proses produksi lebih optimal dan tidak memakan waktu yang lebih lama.

d. Untuk penelitian berikunya perlu mempertimbangkan ilmu ekonomi teknik dalam mendesain suatu produk. 


\section{DAFTAR PUSTAKA}

Naik dkk, 2014. Meminimalkan cacat sink mark dengan proses injection molding menggunakan metode Taguchi. Yogyakarta: UMY

Nakazawa, M. 1990. "Mold Basic Design Text Book" . Indonesia Mold \& Dies Industry Association (IMDIA), JETRO (Japan External Trade Organization).

Sugondo, A. 2007. Minimalisasi Cacat dengan Pengaturan Tekanan Terhadap Kualitas Produk pada Proses Injection Molding dengan Menggunakan Simulasi. TEKNO SIM 2007. Yogyakarta: UGM.

Stevens, Malcolm P. 2001. Kimia Polimer. Jakarta : Pradnya Paramita.

Kale, H.P., dan Umesh V.H. 2015. Optimization of Injection Moulding Process Parameters for Reducing Shrinkage by Using High Density Polyethylene (HDPE) Material. Internatinal Jounal of Science and Research. 4(5): 722-725.

Ratmono 2017 . Optimalisasi Parameter Injeksi Untuk Minimasi Shrinkage Sink Marks dan Warpage Pada Industri Mold Modern. Yogyakarta : Atma Jaya

Darmawan, J. 2018. Pengaruh Variasi Suhu Terhadap Cacat Short Shot Pada Produk Injection Molding Berbahan Polypropylene (PP).

Djunarso. 2011. Dasar Mold Design. Surakarta.

Andhy Rinant Dkk, 2012, " Desain Ulang Unit Pemanas Dan Pengendali Kecepatan Injeksi Mesin Molding" Universitas Sebelas Maret

Irwan Yulianto, 2014, "Rancangan Desain Mold Produk Knob Regulator Kompor Gas Pada Proses Injection Molding" Jurusan Teknik Industri Institut Teknologi Nasional (Itenas) Bandung

Rudiyadi, Raswan. 2016. Optimasi Filling Time Injection Molding Crisper Dengan Bantuan Software Autodesk Moldflow Insight, Universitas Mercu Buana Jakarta.

Moerbani, J., 1999, Plastic Moulding, Jurnal Akademi Teknik Mesin Industri (ATMI), Surakarta.

Anggono, A.D., 2005, Prediksi Shrinkage Untuk Menghindari Cacat Produk Pada Plastic Injection, Media Mesin Vol. 6 No. 2, Teknik Mesin UMS, Surakarta.

Amelia Sugondo, "Kajian Pengaruh Ketebalan Pada Kualitas dan Mampu Bentuk Dengan Menggunakan Simulasi Pada Proses Injection Molding (Studi Kasus: Model Gelas)," dalam Seminar Nasional Teknik Mesin 3 , Surabaya, 2008, pp. 1-5.

Colin Hindle. Polypropylene. http://www.bpf.co.uk/plastipedia/polymers/pp.aspx. akses tanggal 11 November 2015 
Jurnal Inkofar * Volume 1 No. 2 Desember 2020 * ISSN: 2615-3645 (Print) / 2581-2920 (Online) Tersedia secara online di: http://www.politeknikmeta.ac.id/meta/ojs/

\section{LAMPIRAN}

Tabel Spesifikasi Mesin Injeksi

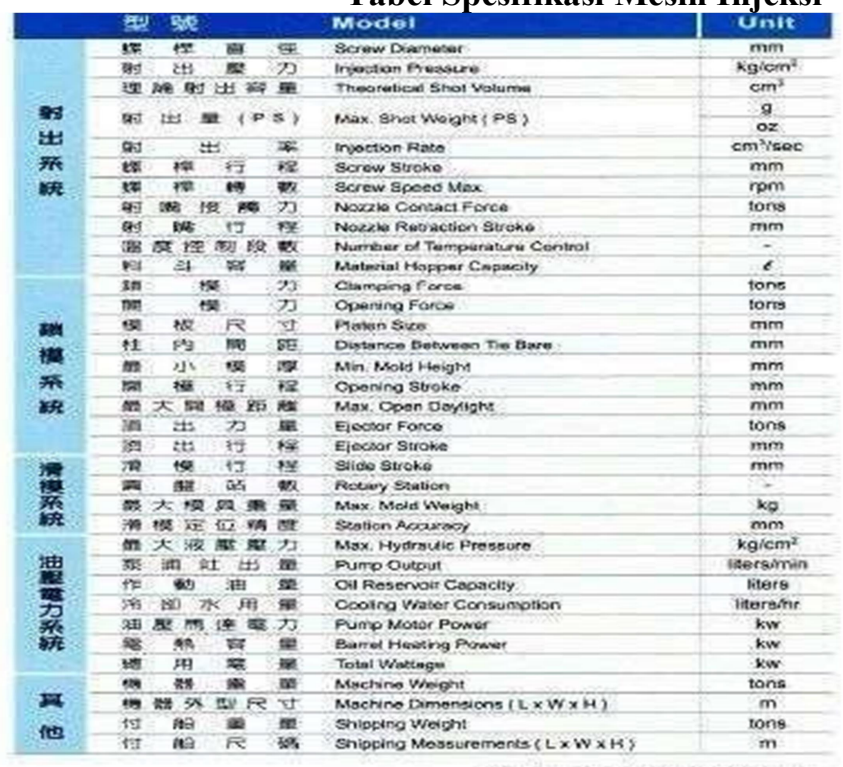

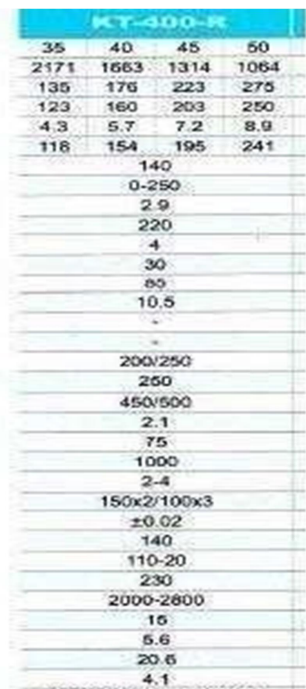

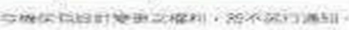

$2750 \times 1600 \times 273012790$ 
Jurnal Inkofar * Volume 1 No. 2 Desember 2020 * ISSN: 2615-3645 (Print) / 2581-2920 (Online) Tersedia secara online di: http://www.politeknikmeta.ac.id/meta/ojs/

Mold Frame Pick Up Right
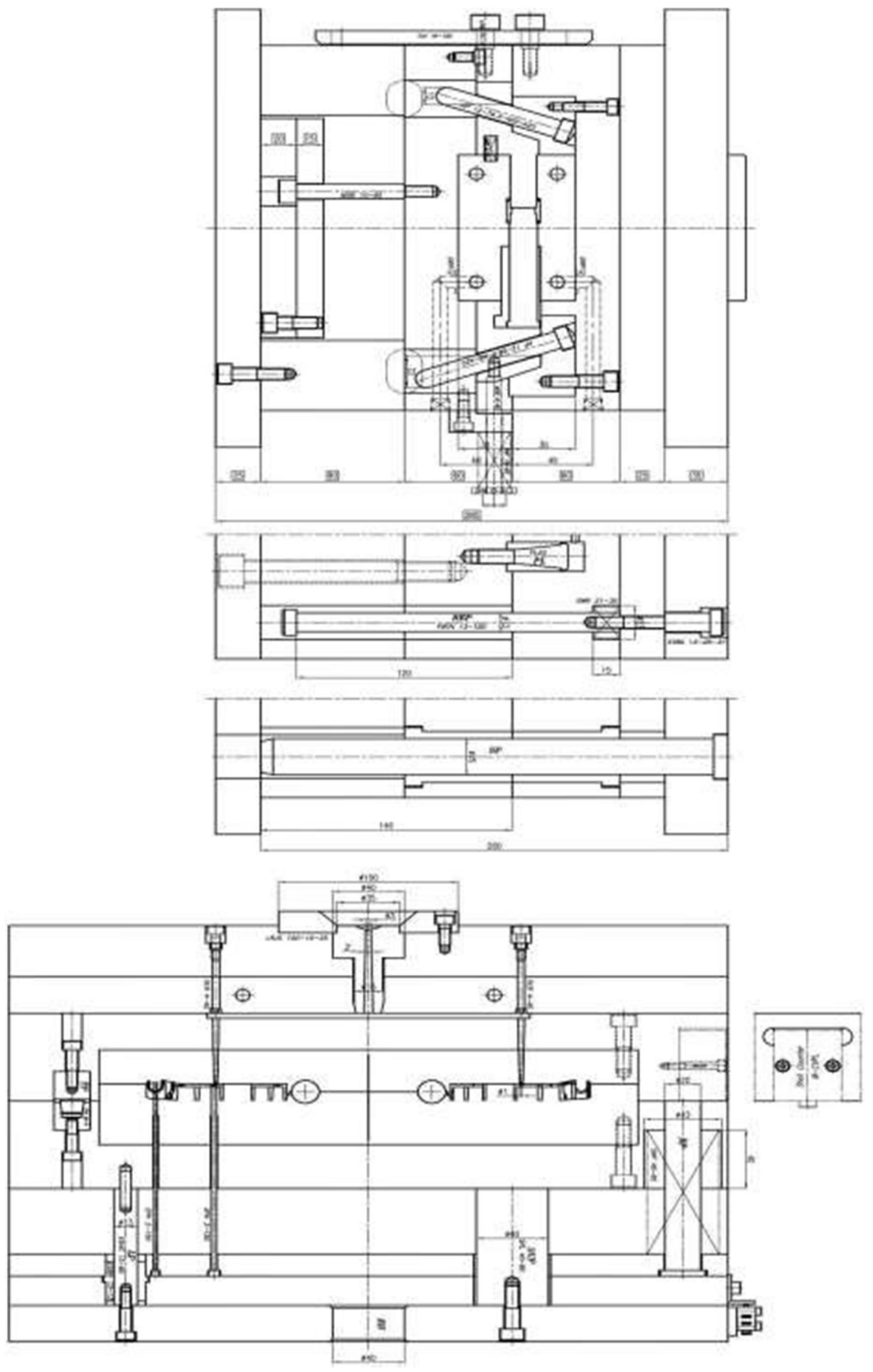
Jurnal Inkofar * Volume 1 No. 2 Desember 2020 * ISSN: 2615-3645 (Print) / 2581-2920 (Online) Tersedia secara online di: http://www.politeknikmeta.ac.id/meta/ojs/

\section{Cooling System Mold}
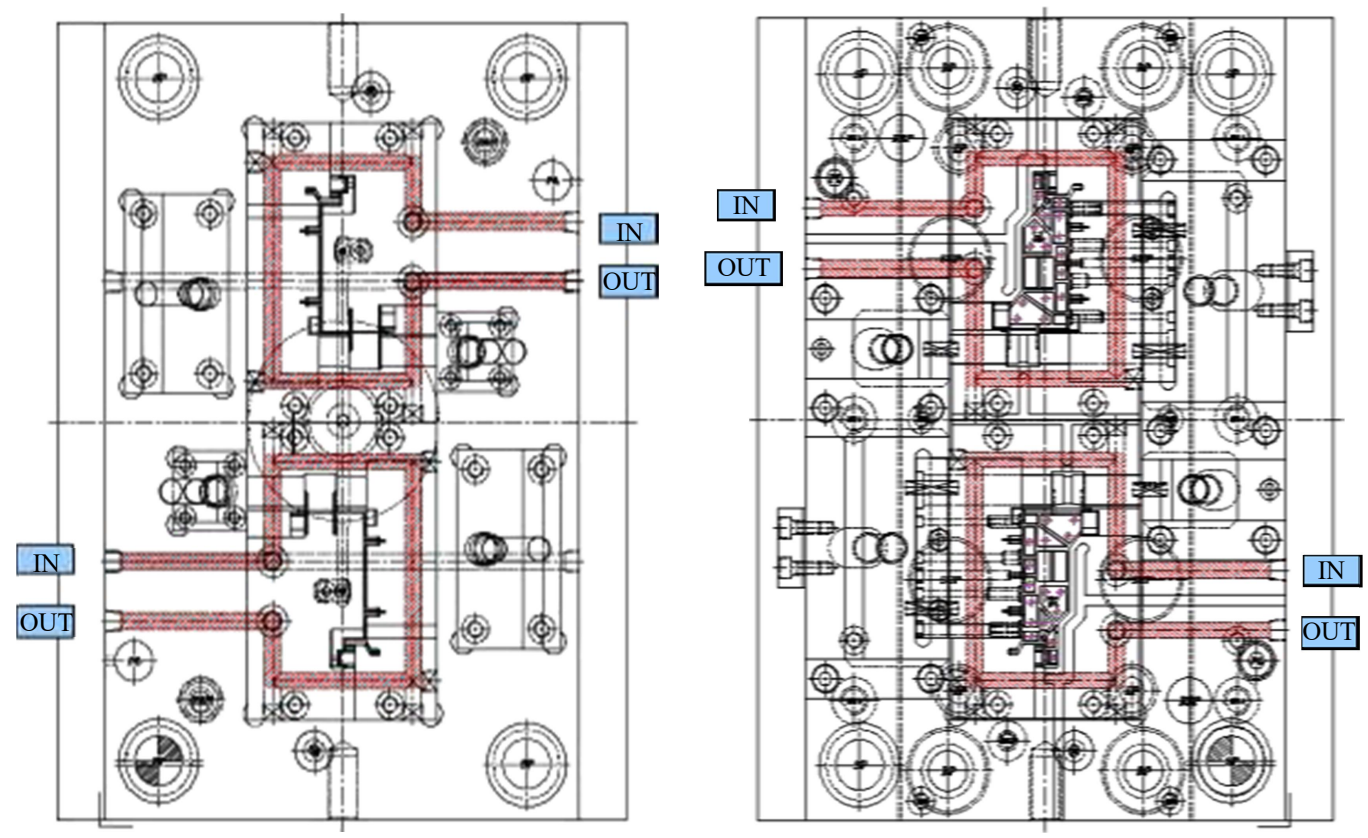

Insert Cavity Core Area
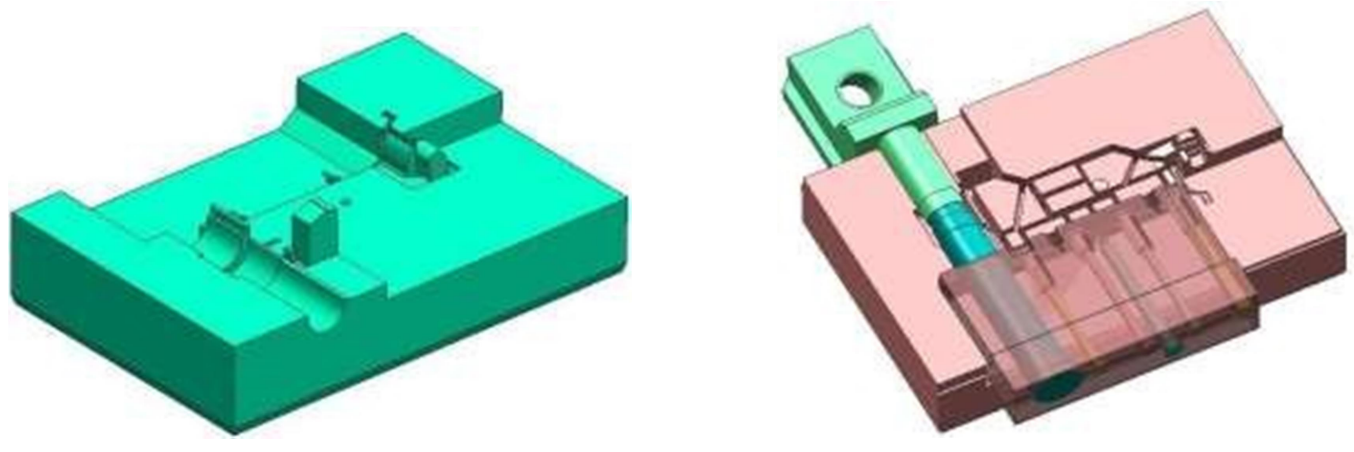

(C) 2020, Jurnal InkofarAll Rights Reserved 